\title{
Correction to: Strategies to Reduce Errors Associated with 2-Component Vaccines
}

\author{
Farzana Samad ${ }^{1} \cdot$ Samantha J. Burton ${ }^{1} \cdot$ Diana Kwan $^{2} \mathbb{D} \cdot$ Noah Porter $^{2} \cdot$ Judy Smetzer $^{1} \cdot$ Michael R. Cohen $^{1}$. \\ Jeanne Tuttle ${ }^{3} \cdot$ Danial Baker $^{4} \cdot$ Dennis E. Doherty ${ }^{5}$
}

Published online: 6 January 2021

(c) Springer Nature Switzerland AG 2021

\section{Correction to: Pharmaceutical Medicine https://doi.org/10.1007/s40290-020-00362-9}

An Online First version of this article was made available online at https://link.springer.com/journal/40290/online-first on 5 November 2020.

The original version of this article unfortunately contained a mistake.

In Section 9, Report Events and Concerns: The text that reads:

"Unnoticed errors will not be reported. Manufacturers are required to report errors to the FDA, but in the healthcare setting it is voluntary. Healthcare professionals should be encouraged to report both internally and externally."

The original article can be found online at https://doi.org/10.1007/ s40290-020-00362-9.

\section{Diana Kwan}

dck@usp.org

Institute for Safe Medication Practices, Horsham, PA, USA

2 United States Pharmacopeia, Rockville, MD, USA

3 Department of Veterans Affairs, Pharmacy Benefits Management Services, Washington DC, USA

4 College of Pharmacy and Pharmaceutical Sciences, Washington State University, Spokane, WA, USA

5 Division of Pulmonary, Critical Care, and Sleep Medicine, University of Kentucky, College of Medicine and Chandler Medical Center, Lexington, KY, USA
Should read:

"Unnoticed errors will not be reported. Healthcare professionals should be encouraged to report both internally and externally."

The original article has been corrected. 